\title{
Reconstruint identitats i noves quotidianitats. El cas d'un grup de dones espanyoles a Ciutat de Mèxic
}

\author{
Anna Ortiz Guitart \\ Universitat Autònoma de Barcelona. Departament de Geografia \\ anna.ortiz@uab.cat \\ Cristóbal Mendoza \\ Universidad Autónoma Metropolitana. Departamento de Sociología \\ Iztapalapa, México DF \\ cmp@xanum.unam.mx
}

Rebut: 26-02-2008

Acceptat: 06-03-2009

\section{Resum}

En aquest article, s'hi presenten els resultats d'una recerca sobre migració qualificada a la Ciutat de Mèxic centrada en un grup de dones expatriades espanyoles. Des d'una perspectiva de gènere, s'hi analitzen les reorientacions laborals i les estratègies de negociació dins les llars d'un grup de dones d'alta qualificació que "acompanyen" els seus marits (o parelles) en el procés migratori. Lluny de considerar-les com a subjectes passius d'aquest procés, l'article les mostra com a agents actius capaços de reformular estratègies per afrontar canvis substancials com a dones, treballadores, esposes i mares al país de destinació. Finalment, també s'hi exposen les principals pràctiques espacials d'aquestes dones, així com algunes percepcions i imaginaris de la Ciutat de Mèxic, que, en general, es relacionen amb la desconfiança i la por.

Paraules clau: migració qualificada, dones expatriades, vida quotidiana, Mèxic, Espanya.

Resumen. Reconstruyendo identitdades y nuevas cotidianidades. El caso de un grupo de mujeres españolas en Ciudad de México

En este artículo, se presentan los resultados de una investigación sobre migración calificada llevada a cabo con un grupo de mujeres expatriadas españolas residentes en Ciudad de México. Desde una perspectiva de género, se analizan las reorientaciones laborales y las estrategias de negociación dentro de los hogares de un grupo de mujeres de alta calificación que "acompañan" a sus maridos en el proceso migratorio. Lejos de considerarlas como sujetos pasivos de este proceso, el artículo nos las muestra como agentes activos capaces de reformular estrategias para afrontar cambios substanciales como mujeres, trabajadoras, esposas y madres en el país de destino. Finalmente, también se exponen las principales prácticas espaciales de estas mujeres y algunas percepciones e imaginarios de la Ciudad de México, que, en general, se relacionan con la desconfianza y el miedo.

Palabras clave: migración calificada, mujeres expatriadas, vida cotidiana, México, España. 
Abstract. Reconstructing identities and new daily routines. The case of a group of Spanish women in Mexico City

The article presents results of a research on skilled migration that was carried out with Spanish female expatriates in Mexico City. From a gender perspective, the article analyzes work experiences and processes of negotiation within the househould for a group of highly-skilled professional women who "accompany» their husbands (or partners) in a family migration to Mexico. Instead of viewing these women as mere passive agents, the article examines the ways how these female migrants are able to re-elaborate strategies to face up new challenges as women, workers, wives and/or mothers in the destination country. Finally, it explains their everyday activities and geographical perceptions of Mexico city which is generally perceived as potentially dangerous.

Key words: skilled migration, female expatriates, daily life, Mexico, Spain.

\author{
Sumari \\ Metodologia i treball de camp \\ La sortida del mercat laboral. \\ Entre el sentiment de pèrdua i el desig \\ $\mathrm{d}^{\prime}$ "autodescobriment" personal \\ Vida quotidiana. \\ Viure «en una bombolla» \\ Reflexions finals \\ Referencies bibliogràfiques
}

Des dels anys vuitanta, l'anàlisi de les dones migrants ha estat incorporada a l'extensa literatura sobre migracions (temes relacionats amb els motius de la migració, la incorporació laboral de les dones immigrants o, més recentment, els canvis en les relacions de gènere com a conseqüència dels processos migratoris; Chant i Radcliffe, 1992; Momsen, 1992; Sharpe, 2002; Pessar i Mahler, 2003; Sinke, 2006; Donato et al., 2006). Aquesta literatura subratlla que les dones s'incorporen a la migració internacional com a treballadores i agents actius del procés migratori, i no forçosament dins d'esquemes de reagrupació familiar. En aquest sentit, s'observa que la seva incorporació laboral es dóna sobretot en activitats tradicionalment associades a les dones, com ara la indústria tèxtil (Ortiz, 1996), el sector de la neteja o el servei domèstic (Momsen, 1999; HondagneuSotelo, 2001). La incorporació d'aquestes treballadores estrangeres en aquests nínxols laborals s'ha vist afavorida en alguns contextos geogràfics, com ara el sud d'Europa, per l'entrada de dones no migrants en el mercat laboral i, en conseqüència, per l'expansió del sector domèstic (vegeu, referent al cas d'Itàlia, Chell, 2000; de Grècia, Cavounidis, 2006; o al conjunt del sud d'Europa, Mendoza, 2003) i per unes polítiques migratòries que, fins a cert punt, limiten l'accés dels migrants al mercat laboral a feines de baixa qualificació que, en general, són poc valorades per la població autòctona (per exemple, els serveis personals o el treball domèstic; vegeu Hondagneu-Sotelo, 2001; Oertzen, 2003; Piper, 2006).

Des d'una perspectiva demogràfica, també s'ha donat molt de pes a l'estudi de la incorporació laboral de les dones migrants (Donato, 1992; Strum i 
Tarantolo, 2003), de manera que alguns autors fins i tot han parlat d'una feminització de les migracions. Aquest procés, en efecte, es pot observar en contextos geogràfics concrets (la migració filipina dominada àmpliament per dones, Ribas, 1999; o la dominicana, Ariza, 2000). No obstant això, potser és arriscat afirmar la generalització d'aquesta pauta o dir que la feminització dels fluxos és un fet consumat i/o irreversible. A tall d'exemple, els fluxos migratoris que tenen el seu origen a Mèxic encara estan dominats per homes, malgrat que alguns autors insisteixen en la importància de la incorporació de les dones en aquests fluxos (Cornelius, 1992; Marcelli i Cornelius, 2001; Lozano, 2002). De fet, el percentatge de dones en el conjunt de la migració de Mèxic i els Estats Units s'ha mantingut estable als anys noranta (Durand et al., 2001) i només representa el 30\% del total de la dècada (Mendoza, 2005).

Els estudis de migració també han incorporat la perspectiva de gènere, no definida com una variable, sinó com «una sèrie de processos socials que organitzen les pautes migratòries» (Hondagneu-Sotelo, 1994: 3). D’aquesta manera, la migració femenina només es pot comprendre si contempla, a més dels aspectes relatius al mercat laboral, les jerarquies de poder i les expectatives socioculturals associades al gènere (Chant i Radcliffe, 1992). En aquest sentit, algunes recerques emfatitzen els processos d'empoderament de les dones, tant en els països de destinació (referent als Estats Units, vegeu Pedraza, 1991; HondagneuSotelo, 1994; Pessar, 1995, i Foner, 1997), com en les comunitats d'origen on l'emigració dels homes provoca un accés més accelerat i intens de les dones al mercat laboral local (Arizpe i Aranda, 1986; Chant i Radcliffe, 1992); i d'altres estudien els canvis en les relacions de gènere com a conseqüència de la migració internacional o els conflictes que poden derivar-se d'aquest procés (Prieto, 1992; Hondagneu-Sotelo, 1994; Foner, 2001; Donato et al., 2006).

D'altra banda, les teories feministes i postcolonials, com també, en general, les noves geografies culturals, han introduït, en les últimes dècades, noves perspectives per apropar-se a l'estudi de les migracions. La importància donada al «lloc» i a la diversitat d'identitats (segons edat, classe, ètnia, condició sexual o habilitats físiques) ha permès visibilitzar una multiplicitat d'experiències migratòries, varietat de pràctiques socials i espacials dels migrants i complexitat dels motius i dels sentiments associats a la decisió de migrar (Halfacree, 2004), així com una nova concepció dels migrants com a subjectes amb identitat de gènere (Silvey i Lawson, 1999).

Sovint es veu la migració de les dones com un procés que comporta conseqüències positives per a les migrants (perquè accedeixen, en molts casos, a nivells més elevats d'autonomia personal i decisió), però, en general, s'oblida que la majoria encara obtenen la residència legal a partir d'esquemes d'agrupació familiar (Boyd i Pikkov, 2005). En aquest context, la literatura sobre migracions dels últims trenta anys, en bona part, ha «encotillat» les migracions femenines en esquemes rígids d'interpretació, potser perquè s'ha centrat majoritàriament en les migrants de baixa qualificació.

De fet, les migrants d'alta qualificació han estat sistemàticament ignorades en la literatura, ja que, en part, s'ha assumit que aquest tipus de desplaça- 
ment és exclusivament masculí i que el paper destinat a les dones és el d'acompanyant. Últimament, però, alguns estudis han analitzat també la migració qualificada des d'una perspectiva de gènere (Iredale, 2005; Kofman i Parvarti, 2005; Nagel, 2005; Raghuram, 2005; Yeoh i Khoo, 1998; Yeoh et al., 2000). Aquesta literatura ha observat que, en molts casos, quan les parelles emigren, les dones abandonen el mercat laboral, renuncien a la seva carrera professional i es «reorienten» cap a l'atenció dels membres de la família (vegeu Yeoh i Willis, 2005a, per a un estudi de cas de dones procedents de Singapur cap a la Xina). Els motius d'aquesta renúncia es troben, en part, en les barreres de gènere que les migrants experimenten a l'hora d'accedir al mercat laboral del país de destinació; barreres, parcialment, basades en les legislacions migratòries i/o laborals d'alguns països que limiten, de forma notable, la incorporació de les esposes (vegeu Purkayastha, 2005, per a una recerca sobre dones índies als Estats Units). D'aquesta manera, algunes dones amb nivells alts de qualificació i formació pateixen un procés clar de desqualificació laboral, perquè es veuen abocades a acceptar feines per sota del seu grau d'estudis o qualificació, mal pagades i/o a temps parcial (vegeu l'estudi de Man, 2004, sobre treballadores xineses a Canadà).

Malgrat la notable incorporació de dones a feines de responsabilitat i gestió en els últims anys, el nombre d'expatriades continua essent baix, atès que els homes tenen més facilitats per accedir a feines a l'estranger. Les raons d'aquest fet podrien deure's a circumstàncies diverses: 1 ) les treballadores no han aconseguit encara feines d'alta responsabilitat a les empreses o la seva arribada a càrrecs importants de gestió és recent; 2) la percepció, per part de la direcció de moltes empreses, que els llocs de treball a l'estranger són «massa arriscats» perquè les dones puguin fer-se'n càrrec (McDowell i Court, 1994), i 3) les dones no desitgen aquests llocs a l'estranger, ja que una promoció podria implicar més responsabilitat i compromís, i, en conseqüència, més hores de dedicació a l'empresa i menys temps per a atendre les responsabilitats familiars i domèstiques (les quals sembla que, encara avui, hagin de recaure únicament en la seva persona). No sorprèn, doncs, que les parelles que acompanyen els expatriats siguin habitualment dones.

En aquest context, l'article té com a objectiu entendre millor les característiques de la migració qualificada a Mèxic i, d'aquesta manera, se centra en un grup de dones expatriades (esposes d'expatriats de transnacionals) residents a Ciutat de Mèxic, i visibilitza les vivències d'aquestes dones que renuncien a la seva vida professional en benefici de la seva parella. Concretament, l'article analitza les experiències laborals $\mathrm{i}$ les pràctiques quotidianes i espacials d'un grup de dones espanyoles d'alta qualificació a la Ciutat de Mèxic. El text s'estructura en quatre parts. En primer lloc, s'hi presenta breument la metodologia emprada, així com el perfil de les dones entrevistades i el context on es realitza la investigació. Posteriorment, s'hi mostren els resultats principals del treball empíric, fent un èmfasi especial en els aspectes relacionats amb les motivacions per migrar, així com en les experiències laborals i pràctiques (i imaginaris) espacials de les dones expatriades. I, finalment, s'hi exposen unes reflexions finals. 


\section{Metodologia i treball de camp}

\section{Perfil de les dones entrevistades}

En aquest article, hi presentem part dels resultats obtinguts en una recerca portada a terme entre 2005 i 2006 a la Ciutat de Mèxic ${ }^{1}$. El treball de camp es va fer a partir d'entrevistes en profunditat a un total de 54 persones espanyoles (17 homes i 37 dones) residents a la capital mexicana. Diferents treballs d'aquesta recerca ja han estat publicats (vegeu Mendoza i Ortiz, 2006 per a l'estudi de les trajectòries laborals, i Ortiz i Mendoza, 2007 i 2008, centrat en la vida quotidiana i els espais viscuts). Ens centrarem concretament en les 27 dones expatriades que han «acompanyat» els seus marits a Mèxic ${ }^{2}$. Malgrat que la decisió és presa conjuntament pels dos membres de la parella, el motiu essencial per migrar és la feina del marit (o parella). Aquests homes són professionals i ocupen càrrecs de direcció, gerència o són tècnics qualificats d'empreses transnacionals. L'alt perfil educatiu i professional dels marits és compartit per bona part de les esposes (de les 27 dones, 21 són llicenciades o diplomades d'universitat ${ }^{3}$ ). El temps de residència a Mèxic d'aquestes famílies és d'una mitjana aproximada de quatre anys ${ }^{4}$.

Es va contactar amb les dones entrevistades a partir de la tècnica de la bola de neu, i les converses es van gravar i transcriure totalment. L'entrevista gira al voltant de diversos temes, com ara les experiències laborals, la valoració del treball dels dos membres de la parella dins la unitat familiar, les motivacions per

1. L'objectiu general de la recerca ha estat analitzar com la construcció del «lloc» i el desenvolupament del sentit de lloc (pertinença associada a un "lloc») influeix en els processos migratoris. Particularment, s'hi analitza, pel que es refereix al cas dels residents espanyols a Mèxic, les seves trajectòries laborals i migratòries, i s'hi explora com aquestes vivències, idees i sentiments relacionats amb els llocs poden condicionar la seva estada, més o menys llarga, al nou país de residència.

2. De la resta de dones (un total de deu que van fer una migració autònoma), quatre van arribar a Mèxic amb la intenció de passar-hi uns quants dies (visitar-hi amics, familiars o la parella mexicana) i, per diferents circumstàncies, van allargar l'estada al país i hi van acabar trobant feina; i sis més hi van arribar becades per treballar en organismes internacionals i espanyols (Nacions Unides, oficines de promoció del comerç exterior basc, català, etc.) i van obtenir, quan va finalitzar la beca, contractes laborals temporals o indefinits (vegeu Mendoza i Ortiz, 2006).

3. Les entrevistades han estudiat medicina, ciències de la comunicació, publicitat, dret, enginyeria industrial, econòmiques, direcció i administració d'empreses, filosofia, història de l'art, filologia hispànica, empresarials, infermeria, pedagogia, logopèdia, educació infantil, educació musical, educació especial i treball social. N'hi havia tres que, en el moment de fer l'entrevista, estaven ampliant la seva formació cursant una llicenciatura de psicologia a la Universidad Nacional de Educación a Distancia (UNED), un postgrau de gestió cultural a la Universitat Oberta de Catalunya (UOC) i un mestratge d'administració d'empreses a la Universidad Iberoamericana (una de les universitats privades més prestigioses de Mèxic).

4. Normalment, el personal expatriat es queda al país de destinació entre quatre i sis anys. Quan s'acaba aquest període, les empreses decideixen reinserir el personal expatriat al país d'origen o ressituar-lo en un altre país on sigui necessari reorganitzar una secció de la mateixa empresa, formar equips nous o obrir mercats nous. 
traslladar-se a viure a l'estranger, les estratègies seguides per compatibilitzar les responsabilitats familiars i domèstiques, així com les activitats quotidianes $\mathrm{i}$ pràctiques espacials a la ciutat mexicana. Cal comentar que el fet que els autors d'aquesta recerca fóssim catalans va facilitar molt el primer contacte amb aquestes dones (residents a Catalunya i Madrid, majoritàriament), així com la trobada posterior a casa d'elles i la conversa mantinguda (aproximadament durant 75 minuts) sobre els diferents temes. En aquest sentit, el fet que moltes de les experiències laborals, socials, quotidianes i espacials fossin compartides per l'entrevistada i la persona entrevistadora, va crear un clima de confiança i d'identificació molt adient per al bon desenvolupament de la conversa. Alhora, el fet que l'entrevista es realitzés a casa d'aquestes dones, va permetre que el treball de camp s'enriquís amb l'observació participant, ja que, com assenyala Oberhauser (1997), l'entrevista no només representa el moment per recollir informació mitjançant preguntes adients, sinó que, a més, és una bona oportunitat per observar el «lloc» on es fan les entrevistes (el context espacial; la casa en el nostre cas), ja que pot donar informació rellevant sobre la construcció de les identitats d'aquestes persones (Sin, 2003). Així, per exemple, les dimensions de les cases (entre 200 i 400 metres quadrats de mitjana, algunes amb jardí), la decoració d'aquestes (quadres, escultures, fotografies, etc.) o la presència d'altres persones (concretament, els fills i les filles i les persones del servei domèstic) van donar una informació visual (relacionada especialment amb el seu nivell socioeconòmic) que complementava les explicacions i els comentaris de les entrevistades.

Caldria esmentar, també, que totes les dones asseguraven que havien emigrat voluntàriament i n'hi havia una bona part que acceptava el canvi de residència, no només amb il.lusió i com una bona oportunitat per conèixer un nou país i una nova cultura, sinó, sobretot, per «descansar» ${ }^{5}$ d'una vida laboral intensa (i, en alguns casos, "estressant»), per «trencar la rutina» $i$, en els casos de les mares, dedicar-se a temps complet a l'atenció dels més menuts. Afirmaven, doncs, que la decisió de viure a Mèxic havia estat pactada dins la llar i era viscuda com «una aposta per ell però [també com] un benefici per a tota la família» (Teresa, 32 anys) i com «una experiència que dóna comoditat i confort a la família» (Rosa, 57 anys).

Per tant, aquestes dones apunten que la decisió de migrar a Mèxic no és, de cap manera, forçada. Cooke (2003), en aquest sentit, observa que l'«efecte d'arrossegar l'esposa» perquè segueixi les passes del marit es dóna fins i tot en situacions on el nivell socioeconòmic femení és superior al de les seves parelles (com és el cas d'algunes entrevistades). Així, segons aquest autor, les migracions familiars no s'expliquen exclusivament en termes salarials o de promoció laboral, ja que la decisió de migrar no respon a principis igualitaris o completament simètrics, ni els sous dels dos membres de la parella tenen el mateix pes relatiu.

5. Les cometes són per destacar les paraules que utilitzen les pròpies entrevistades. 


\section{Context}

Les grans ciutats de l'Amèrica Llatina s'han integrat plenament al mercat mundial, atès, principalment, el seguiment d'un model basat en el lliure comerç, les exportacions, la privatització d'empreses del sector públic i l'atracció d'inversió estrangera (Sassen, 2000; Aguilar, 2002). Com a conseqüència d'aquestes transformacions econòmiques, aquestes ciutats exerceixen un paper de coordinació i control dels seus mercats nacionals respectius i, a més, es constitueixen en nodes on flueixen els capitals, les informacions, les mercaderies i les persones de diferents nacionalitats i orígens.

En termes de mercat de treball i d'estructura social, la inserció de les ciutats llatinoamericanes dins els processos de globalització de l'economia (i de la cultura, com assenyala García Canclini, 1995) ha suposat una polarització més gran dels ingressos i un augment de les desigualtats. Les polítiques econòmiques de liberalització i desregularització han deixat també petjada en el paisatge i la morfologia de les principals ciutats llatinoamericanes, que han experimentat importants canvis territorials i urbans (des de la suburbanització i la policentralizació fins a la segregació residencial i la fragmentació de l'estructura urbana, De Mattos, 2002).

A la Ciutat de Mèxic, amb més de 19 milions d'habitants ${ }^{6}$, es veuen reflectides aquestes contradiccions. Per una banda, compleix funcions de ciutat global, al concentrar les seus de les grans empreses nacionals i transnacionals, centralitzar i redistribuir regionalment les inversions estrangeres i aglutinar serveis orientats a la producció (com ara consultories, auditories o agències de publicitat), que esdevenen molt útils per a l'engranatge dels processos de globalització (Parnreiter, 2002). Per altra banda, la periferia metropolitana creix acceleradament i apareixen centres suburbans nous, alhora que, paral-lelament, s'observa una fragmentació social i urbana més gran al seu territori (urbanitzacions de luxe localitzades en barris molt pobres, nous complexos comercials disseminats per la ciutat i barris marginals enclavats enmig d'altres de classe alta) (Borsdorf, 2003; Hiernaux, 1999).

Precisament, les dones expatriades entrevistades i les seves famílies viuen a l'oest de la Ciutat de Mèxic, als barris de Santa Fe-Interlomas ${ }^{7}$ (mapa 1), en pisos i cases unifamiliars molt luxoses amb altes mesures de seguretat (en àrees sovint tancades conegudes com a gated communities $^{8}$ ) (vegeu fotografies 1 i 2).

6. D'acord amb les dades del Conteo de Población y Vivienda (INEGI, 2008), la població a Mèxic Districte Federal era de 8.720.916 habitants l'any 2005; a l'Àrea Metropolitana de la Ciutat de Mèxic (DF i municipis que són una conurbació del veí Estat de Mèxic), de 19.231.829 habitants, al voltant del 20\% de la població total del país (de 103.263.388 habitants).

7. Santa Fe-Interlomas és una àrea situada a l'oest de la Ciutat de Mèxic entre la delegació de Cuajimalpa i el municipi de Huixquilucan, a l'Estat de Mèxic. És una de les zones de la ciutat més dinàmiques en termes econòmics (hi ha moltes empreses mexicanes i transnacionals que hi tenen la seu) i immobiliaris (s'hi troben nombrosos edificis residencials i oficines de luxe).

8. Els complexos residencials de Santa Fe-Interlomas esdevenen una «manifestació espacial postmoderna de la fragmentació de l'espai urbà en àrees parcials independents» (Janoshcka, 2002) i és un «exemple d'un urbanisme que sembla obsessionat per trencar la ciutat a trossos, per aillar la gent, segregar-ne els grups socials, tancar-los en guetos» (Borja i Muxí, 2001, 340). 


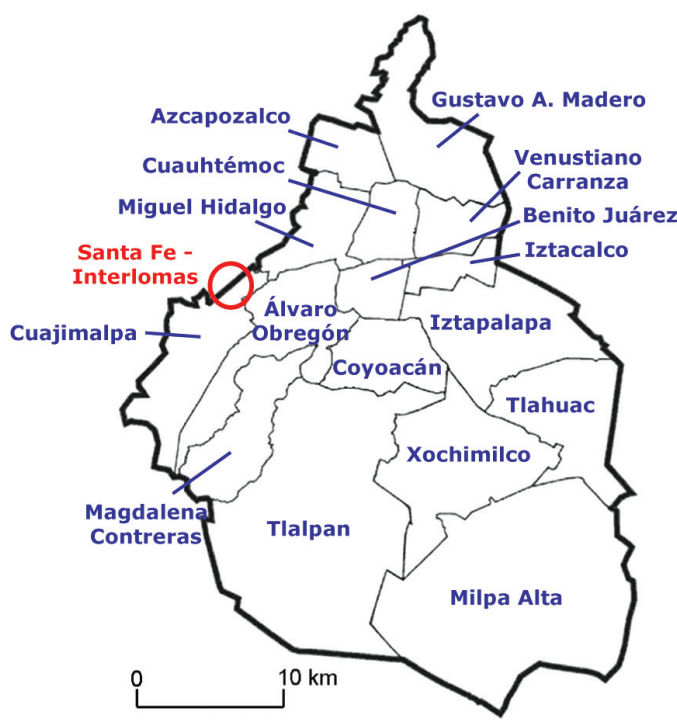

Mapa 1. Localització de Santa-Fe Interlomas. Font: elaboració pròpia.

La sortida del mercat laboral. Entre el sentiment de pèrdua i el desig d' «autodescobriment" personal

En una recerca anterior, vam veure que, pels expatriats, la promoció laboral, associada a un augment salarial, és la raó principal per migrar a Mèxic (Mendoza i Ortiz, 2006). Aquesta migració es planteja com a temporal i beneficiosa per a la carrera professional de l'expatriat. Bona part d'aquests professionals d'alta qualificació estan casats (o viuen en parella) i arriben a la destinació acompanyats de les seves esposes (i criatures menors d'edat). A més del sou i la promoció, també gaudeixen de les facilitats proporcionades per l'empresa relacionades amb la cobertura d'una sèrie de despeses, com ara el lloguer de l'habitatge, la dotació d'un vehicle, la matrícula de l'escola dels fills i les filles i els viatges anuals a Espanya.

La primera conclusió que es deriva de l'anàlisi de les dones entrevistades rau en la complexitat de la relació entre les trajectòries laborals dels marits i els arranjaments familiars. De fet, per a pràcticament la meitat de les entrevistades, Mèxic no és la primera experiència migratòria familiar, sinó que és una més de les realitzades com a part d'una estratègia deliberada de promoció laboral del marit dins la companyia transnacional. És també destacable que moltes dones prefereixen l'opció de migrar a uns altres tipus d'arranjaments familiars, com ara la separació temporal de la família o la mobilitat continuada del marit per feina (per exemple, els casos en què les dones es queden a Espanya i els homes es desplacen temporalment i periòdicament a treballar 


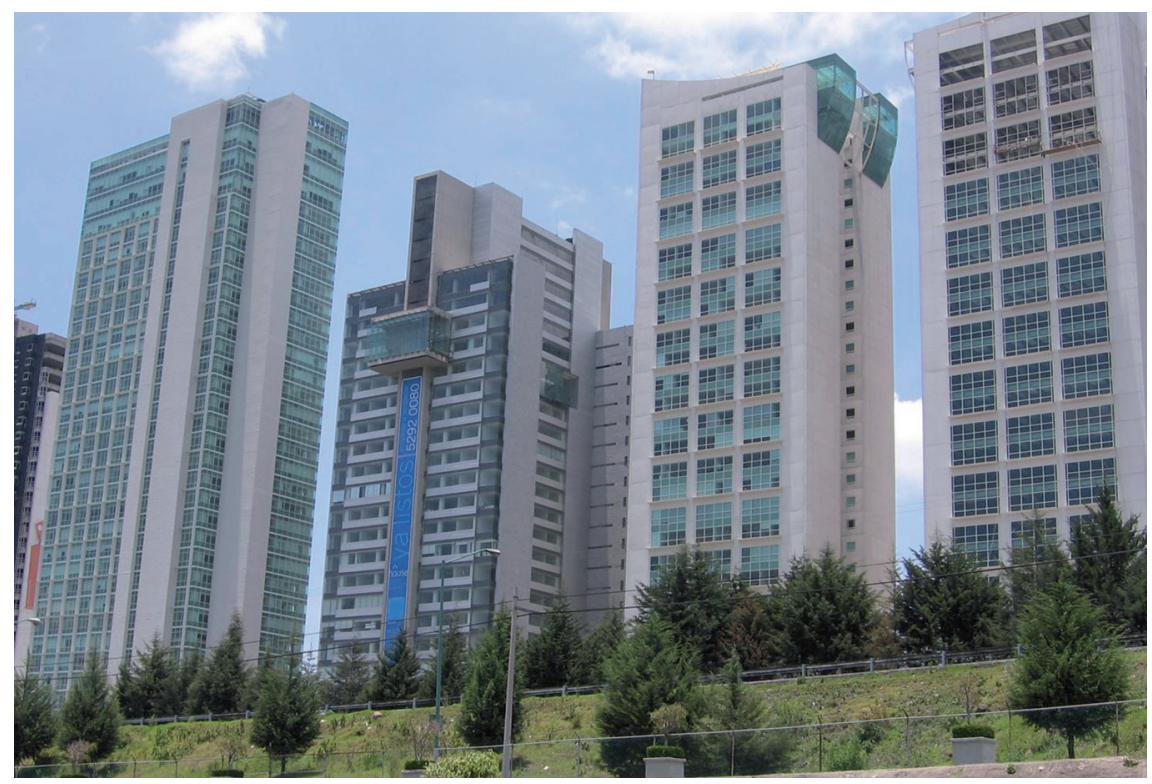

Fotografia 1. Oficines a Santa Fe (Ciutat de Mèxic). Font: treball de camp, 2 de juliol de 2006.

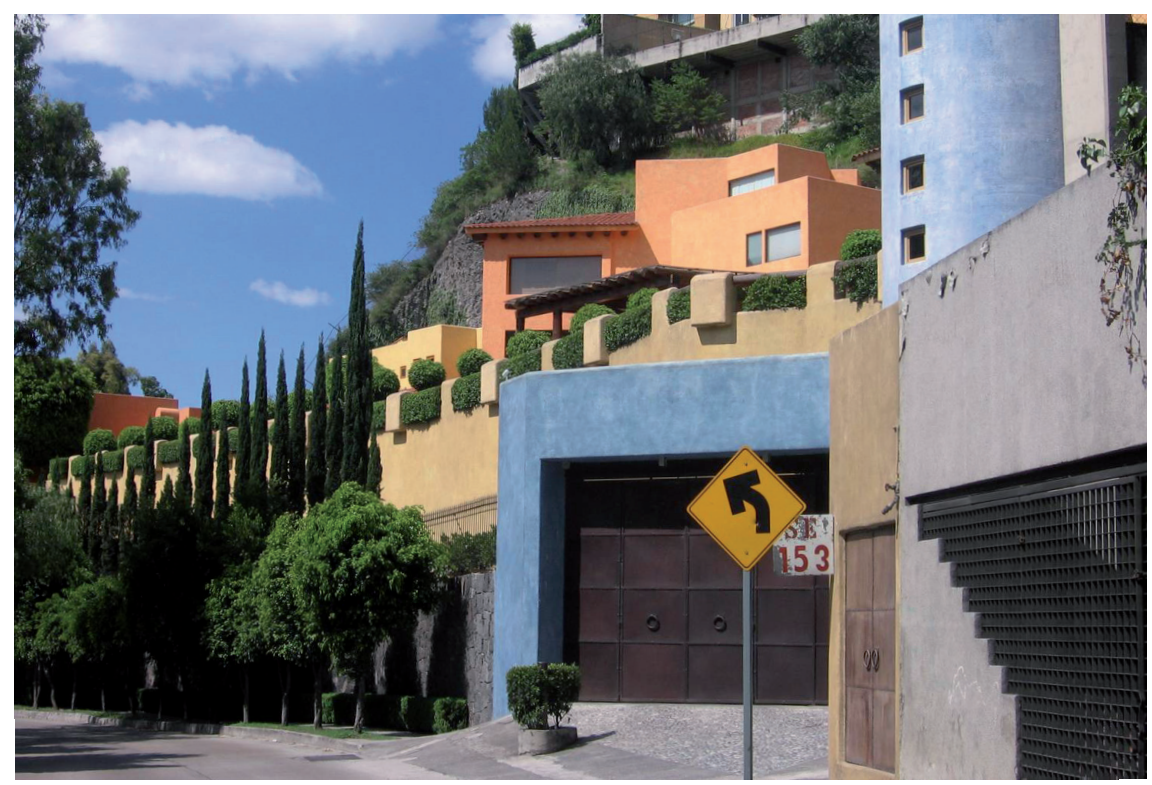

Fotografia 2. Cases unifamiliars a Interlomas (Ciutat de Mèxic). Font: treball de camp, 2 de juliol de 2006. 
a uns altres països). Aquesta darrera opció esdevé estressant per al marit i desgastant per al conjunt dels membres de la família. La Marina (43 anys) comenta que el marit «es passava la setmana a Brussel.les i venia només els caps de setmana a Madrid. Treballava en una multinacional francesa i tenia despatx a Anvers i a Madrid». D'aquesta manera, l'oportunitat de venir a Mèxic la va viure com un «respir, en el sentit que estaríem, finalment, junts».

Si bé és veritat que una bona part de les dones expatriades entrevistades no treballa de manera remunerada a Mèxic, també ho és que la situació laboral de totes és força complexa i va més enllà d'una simple renúncia al mercat laboral. Així, per exemple, trobem dones que no treballen, d'altres que mantenen vincles laborals amb el país d'origen; dones que han decidit muntar la seva pròpia empresa ${ }^{9}$ o que han aconseguit un contracte laboral, i algunes que realitzen feines, de baixa remuneració i sense contracte, relacionades amb el seu perfil professional ${ }^{10}$. Vegem aquestes experiències més detalladament.

Hi ha un parell d'empresàries que tenen veritables vides transnacionals, ja que continuen treballant a Espanya i tenen establerta una pauta de mobilitat periòdica entre tots dos països. L'una és l'Alícia, de 43 anys. Viatja una setmana al mes a Madrid per atendre personalment els seus clients i gestionar l'empresa, que és administrada pels seus treballadors durant la seva absència. Dues més han aconseguit un contracte de treball i han experimentat, com les seves parelles, una mobilitat laboral ascendent ${ }^{11}$. Per exemple, l'Elisa ha arribat a ser subdirectora d'una empresa espanyola i va aconseguir aquesta feina en una festa organitzada per uns coneguts espanyols. Ho explica amb aquestes paraules:

—Vam venir a Mèxic perquè al meu xicot li van oferir feina aquí. Va ser una oportunitat bona per a ell. La feina que jo feia en aquell moment tampoc no em motivava gaire i vaig dir "provem-ho". D'això ja en fa quatre anys.

- I al venir a treballar a Mèxic, va millorar la teva situació laboral?

- Sí, perquè aquí l'espanyol està molt ben considerat..., o l'espanyola. Més l'espanyol que l'espanyola ${ }^{12}$. Jo sóc ara subdirectora i tinc al meu càrrec entre 40 i 50 persones. El meu cap viu a Madrid i nosaltres portem l'oficina. A Espanya, als 25 anys, que és l'edat que tenia quan vaig començar a treballar aquí, és impossible tenir un càrrec així.

9. Aquestes dones han muntat les seves pròpies empreses (una escola de ball i una consultoria) amb socis mexicans.

10. Aquestes dones treballen algunes hores a la setmana, no tant pels ingressos (ja que el sou que reben és gairebé simbòlic), sinó pel fet, diuen, de «sentir-se útils», d'ocupar el seu temps i, sobretot, perquè els agrada. De la mateixa manera que mostren els resultats de Perista (2000) per a un grup d'expatriades europees a Portugal, aquestes dones fan unes feines molt menys qualificades que les que tenien al seu país d'origen. Es tracta, en el nostre cas, d'una musicòloga que imparteix classes particulars de piano als fills i a les filles dels seus amics; d'una pedagoga que fa classes particulars de castellà a una noia coreana i d'una mestra especialitzada en educació musical que imparteix classes de música a l'escola del seu fill.

11. A Mendoza i Ortiz (2006), s'hi tracta aquest tema més detalladament.

12. El tema del masclisme a Mèxic surt a les entrevistes de manera reiterada. 
- Com vas aconseguir aquesta feina?

- A través de la Cambra de Comerç. En una festa d'espanyols, hi vaig conèixer una noia que treballava a la Cambra de Comerç i li vaig dir que estava buscant feina. I ella em va contestar: "Conec un senyor de Madrid, crec que li podries interessar». Vaig fer una entrevista i ja està ${ }^{13}$. Vaig tenir molta sort. (Elisa, 29 anys)

Trobem també dones que inicialment es plantegen incorporar-se al mercat laboral mexicà, animades per les promeses de les empreses dels seus marits per ajudar-les a buscar feina o els desitjos d'aconseguir una experiència laboral al país. Tanmateix, en el moment de ser entrevistades, n'hi havia moltes que no havien trobat cap feina que satisfés veritablement les seves expectatives. En alguns casos, van rebutjar l'oferta laboral perquè els contractes de treball estaven regulats, a diferència dels seus marits, per les condicions mexicanes (amb menys dies de vacances i salaris més baixos), o perquè les feines eren només a temps complet $i$ aquest fet era incompatible amb la cura dels fills.

Potser ignorant que, a la majoria de països del món, les persones que acompanyen els treballadors immigrants només tenen dret a la residència sense feina, algunes dones mencionen que el fet que el seu permís migratori indiqui clarament la seva condició de «dependent econòmic del marit» resulta «impactant» i, fins i tot, «de mal gust». La Marina (43 anys), per exemple, amb el seu permís de residència a les mans, llegeix textualment: «Sexe: femení. Estat civil: casada. Activitat autoritzada: viure al costat i sota la dependència econòmica de X [nom del seu espòs], de nacionalitat espanyola...». I, molt enutjada, continua: «Aquesta és la meva activitat... Quan ho vaig veure, no m'ho podia ni creure... N'hi ha per denunciar-ho! Que deixin de posar-ho! Prefereixo "sus labores”... És denigrant!». En la mateixa línia, la Pilar comenta:

Per a mi no ha estat facil [venir a Mèxic] i he tingut etapes duríssimes: aclimatar-m’hi, pensar que la meva vida era diferent... El primer mes sense sou..., pensar que era «dependent de», això ho diu l'FM3 [nom que rep a Mèxic el permís de residència]. Suposo que hi ha gent que ha fet de mama tota la vida, però jo, com que la meva vida havia estat sempre professional, em trobava com una idiota total. Vaig passar mesos bastant tocada del coco i amb depre. (Pilar, 48 anys)

La sortida del mercat laboral, però, és viscuda per algunes dones, concretament per les funcionàries de carrera, com una bona oportunitat per «oxigenar-se» $i$ «recarregar energies». La migració per a elles és considerada un parèntesi saludable dins la seva trajectòria laboral. Aquestes funcionàries de l'Administració pública (de la Comunitat de Madrid, la Generalitat de Catalunya o de l'Ajuntament de Barcelona) van demanar excedències voluntàries sense sou per absentar-se de la feina durant un temps determinat. Ara gaudeixen 
d'una excedència laboral $i$, per tant, d'una seguretat laboral a la tornada. Segons elles, aquest fet va suposar un motiu essencial per acceptar traslladar-se amb els seus marits a Mèxic.

Com hem comentat, bona part de les entrevistades, però, va deixar la seva feina sense cap garantia de reincorporació quan tornés a Espanya. La sortida del mercat laboral representa un motiu de preocupació per a aquestes dones, que, com hem vist, tenen titulacions d'educació superior i ocupaven càrrecs qualificats. Les dones més joves són les que viuen la pèrdua de feina amb més frustració $i$ angoixa, perquè consideren que el mercat laboral espanyol, molt competitiu, les pot «castigar» per la seva sortida voluntària. En aquest sentit, tot i que és cert que la decisió de migrar va ser presa conjuntament per la parella i que els ingressos familiars augmenten, el que és beneficiós en termes professionals pels homes, no deixa de ser un període d'estancament laboral per a les dones. No obstant això, però, no es pot parlar del «sacrifici» que fan (d'acord amb la terminologia de Bonney i Love, 1991), ja que, durant la seva estada a Mèxic, desenvolupen un seguit d'estratègies, recursos i habilitats que els permeten viure l'experiència migratòria com un període dedicat a l'enfortiment d'aspectes «immaterials", com ara el seu creixement personal o l'augment del temps dedicat als fills i a les filles. Tanmateix, la por per les dificultats de trobar feina quan tornin existeix, especialment associades a la pèrdua de competitivitat relacionada amb la sortida del mercat laboral durant un període tan llarg. Però, potser, el que esdevé més angoixant per a aquestes dones és la pèrdua d'independència econòmica que genera una frustració personal i un sentiment de culpabilitat.

Odio aquesta dependència econòmica tan absoluta que tinc d'ell [...]. Jo he fet una carrera, he estudiat i tinc una preparació... És per això que no em ve de gust ser mestressa de casa. Jo vull tenir una vida professional. És que això és supersaludable a nivell personal... Tenir un lloc per evadir-se... (Blanca, 30 anys)

Nosaltres anem seguim els nostres marits. Jo em sento, a vegades, un "gosset faldiller». A mi no m'agrada. Sincerament, no m'agrada aquest paper. Em fa la sensació de ser una mantinguda. (Noemí, 32 anys)

A vegades em veig com una «dona florer». (Verónica, 48 anys)

Malgrat tot, les dones entrevistades intenten donar un nou sentit a la seva vida, acceptant críticament la seva nova situació, transformant-la a partir d'un replantejament vital i optant per considerar-la una oportunitat de creixement personal ${ }^{14}$ (o «autodescobriment», com assenyalen Thang et al., 2002, en un estudi sobre treballadores japoneses a Singapur).

14. Algunes de les activitats que fan aquestes dones són: cursos d’idiomes, pintura, música, cuina, costura, manualitats i diferents pràctiques esportives. Aquestes activitats són valorades molt positivament per elles, perquè les fa sentir actives i els permet tractar persones de fora de l'àmbit domèstic (vegeu una informació més detallada sobre aquest tema a Ortiz i Mendoza, 2007). 
A Espanya, el treball a temps parcial, la reducció de la jornada laboral per a membres dependents i els ajuts a les famílies permeten que les dones (més que no pas els homes) puguin conciliar millor la doble jornada laboral ${ }^{15}$. A Mèxic, la dificultat de trobar una feina a temps parcial i la manca de les xarxes de suport familiar obliguen aquestes dones a dedicar-se exclusivament a les tasques de responsabilització de les seves criatures (Yeoh i Khoo, 1998, en un estudi d'un grup d'expatriades britàniques a Singapur, arriba a conclusions similars). En aquest cas, i sense gaires opcions més, les dones accepten i assumeixen un rol més tradicional de gènere i s'arriba al que Ho (2006) anomena la «feminització» de la migració, que és donada per un canvi o una redefinició dels rols i les identitats. En aquest tipus de migració, doncs, les dones expatriades d'alta qualificació es troben en desavantatge respecte als seus marits, ja que, per a elles, és molt més difícil «reconstruir» les seves vides en un país estranger (Purkayastha, 2005). No només subordinen la seva pròpia carrera professional a la del marit, sinó que, a més, són les encarregades de facilitar l'assentament familiar al nou país de residència, reorganitzar les tasques dins la llar i oferir el suport emocional necessari a tots els membres de la família. Així ho expressa una d'elles:

Ell arriba a treballar, el reben i ja té els seus coneguts... Li resulta molt més facil... I [ell] no s’adona que tot el marrón et toca a tu... Buscar col-legi, buscar pis, posar-hi mobles, instal-lar-t'hi, fer que tothom se senti a gust, que el nen no tingui problemes per integrar-se al nou país... Damunt meu recau una cosa que..., en realitat, sempre m'ha recaigut, però no tan ràpid ni tan de cop! (Esperanza, 37 anys)

\section{Vida quotidiana. Viure «en una bombolla»}

La vida quotidiana es desenvolupa en àrees molt determinades de la ciutat que corresponen als entorns més pròxims als llocs de residència, els quals, com ja s'ha comentat més amunt, estan situats als barris més exclusius de la ciutat. El benestar d'aquests barris, expressament protegits i segregats, contrasta fortament amb la precarietat d'altres barris adjacents construïts a les lleres dels turons on viuen sectors pobres de població. Contràriament a la sensació de control que ofereixen les urbanitzacions tancades i els centres comercials vigilats, el conjunt de la ciutat s’imagina com un lloc perillós, inhòspit i insegur. Les grans dimensions d'aquesta, la seva morfologia i, sobretot, els discursos sobre la inseguretat $i$ la violència urbana transmesa des dels mitjans de comunicació, el context social i, en algun cas, l'experiència personal, ajuden a dibuixar

15. Caldria puntualitzar, però, que si la conciliació es planteja només en termes de fomentar el treball a temps parcial (al qual accedeixen majoritàriament les dones) i facilitar els permisos de «maternitat» (que majoritàriament sol-liciten també les dones), l'únic que s'aconsegueix és perpetuar la desigualtat entre gèneres. La conciliació entre la vida laboral i familiar hauria de donar per descomptat que les consequiències de la maternitat i la paternitat són les mateixes per a les unes que per als altres. 
el mapa de les geografies urbanes de la por i a interioritzar molt bé els consells i les recomanacions per evitar, al màxim, riscos innecessaris:

Ens van donar una quantitat de normes de seguretat quan vam venir cap aquí... Horrorós! Ara ja les compleixes com aquell qui res, però... «Vigila que no portis les targetes de crèdit dintre del billeter, porta només una targeta amb poca quantitat, que si vas al caixer automàtic i et fan el secuestro exprés ${ }^{16}$ no et puguin treure gaire». (Inma, 39 anys)

L'elecció dels barris de residència és determinada, sobretot, per la proximitat amb la feina del marit i el col-legi de les criatures, sense oblidar, però, que són les mateixes empreses transnacionals les que ajuden a buscar l'habitatge i el centre escolar justament en aquestes àrees. Les parelles amb fills i filles són les que escullen més viure en urbanitzacions de luxe (tancades i vigilades), perquè proporcionen sensació de seguretat en una ciutat percebuda com a inquietant, insegura $\mathrm{i}$ incòmoda, $\mathrm{i}$ perquè ofereixen un gran ventall de serveis $\mathrm{i}$ àrees comunitàries per als adults $\mathrm{i}$ els infants (piscines, pistes de tennis, escoles bressol, espais de jocs, ludoteques, etc.). Malgrat tot, aquests barris no satisfan del tot aquestes dones, ja que no poden sortir a passejar, perquè, literalment, les vies de circulació que envolten les urbanitzacions no tenen voreres per als vianants, perquè els únics llocs per passejar són els centres comercials i perquè la mobilitat s'hi veu reduïda al vehicle privat:

A Santa Fe, hi ha poques coses per fer. És molt avorrit [...]. No hi ha carrers per caminar... Són condominis. Surts del condomini i has d'anar amb cotxe. Jo tinc el centre comercial al costat i hi vaig caminant, però fora del centre comercial, no pots fer res sense cotxe. No hi ha carrers per caminar. És com una vida molt a dintre dels condominis, una vida molt tancada. (Lluïsa, 34 anys)

La vida que es fa aquí [a Interlomas] és una vida molt tancada. Una vida que estàs aquí dins de casa, fas les teves activitats en un club tancat, te'n vas a un centre comercial... Sempre tancada [...]. Aquí no agafes mai transport públic, et trasllades amb taxi o amb cotxe. Jo surto de casa, em fico dins del cotxe, vaig al supermercat que tinc dins del centre comercial i torno. (Rosa, 57 anys)

Aquests residents d'alta qualificació no són indiferents al seu lloc de residència, sinó que són plenament conscients de les característiques que té, i és per aquesta raó que desenvolupen una sèrie d'estratègies per viure a la ciutat. La gran desigualtat social i la forta fragmentació urbana de la Ciutat de Mèxic provoca que les «zones de contacte» ${ }^{17}$ amb la població local sigui molt limita-

16. El segrest exprés dura menys d'un dia, serveix per obtenir una recaptació limitada (entre 500 i $5.000 €)$ i s'ha convertit en el tipus de segrest més freqüent a l'Amèrica Llatina. Mèxic és el segon país de l'Amèrica Llatina on es pateix més aquests tipus de segrestos (3.000 d'anuals a Mèxic i 4.000 a Colòmbia) (Aznárez, 2007).

17. Concepte utilitzat per Yeoh i Willis (2005b) per fer referència a la construcció d'espais d'intersecció entre subjectes separats prèviament per espais geogràfics. 
da, atès que el seu cercle social i d'amistats poques vegades va més enllà de les urbanitzacions on viuen, de les escoles internacionals on porten els seus fills i les seves filles i dels clubs socials i esportius on van els caps de setmana. En aquests espais es relacionen, de forma prioritària, amb dones (o famílies) de la seva nacionalitat o amb mexicanes d'una classe social alta. Són molt conscients, però, de les desigualtats socials que es troben a la megaciutat $i$, per tant, senten que viuen «com en una bombolla».

\section{Reflexions finals}

L'estudi de la migració qualificada, des d'una perspectiva de gènere, ens ha permès considerar les dones com a subjectes actius capaços de reformular estratègies per afrontar canvis substancials com a dones, treballadores, esposes $\mathrm{i}$ mares en el nou país de residència. Aquesta recerca ens ha permès visibilitzar una sèrie d'experiències migratòries que, d'una altra manera, passarien inadvertides, atès que són esposes o parelles dels protagonistes «productius» de la migració: els homes expatriats de les empreses transnacionals. Aquestes experiències migratòries no estan exemptes de conflictes i contradiccions $i$, a vegades, s'acompanyen d'un sentiment de pèrdua (feina, familiars, amistats, entorn i vida quotidiana, etc.), però gairebé sempre van acompanyades d'una sensació de guany i enriquiment personal.

La perspectiva de gènere ha permès veure, també, fins a quin punt la migració no respon exclusivament a qüestions econòmiques o consideracions laborals (augment dels ingressos i promoció laboral), sinó que més aviat va acompanyada de decisions consensuades dins la llar a partir d'un conjunt de valoracions individuals, familiars i econòmiques. Per tant, la perspectiva de gènere és imprescindible per entendre de quina manera els papers i les identitats de gènere ajuden a explicar les decisions que es prenen en el si de la unitat familiar en el moment de migrar (Cooke, 2003). La perspectiva de gènere no nega la dimensió econòmica del fenomen, sinó que més aviat emfatitza uns altres aspectes, com ara la dominació masculina dins les famílies, la segmentació laboral basa$\mathrm{da}$ en el gènere i el fet que les dones hagin estat socialitzades tradicionalment per prioritzar la família. D’aquesta manera, tal com afirma Halfacree (1995), la posició secundària de les dones casades en decidir una migració eventual de la família per motius laborals del marit reflecteix la marginació patriarcal de les dones dins el mercat laboral. En aquest procés de negociació, els membres de la llar se situen en posicions diferenciades $i$, en general, les dones acaben valorant més el treball i la promoció laboral del marit (o parella) que la seva pròpia trajectòria professional. No obstant això, les dones expatriades d'alta qualificació, en comptes de ser exclusivament «acompanyants» o subjectes passius en el projecte migratori, són agents actius que negocien aspectes relatius a la mobilitat familiar i que participen activament en les dinàmiques familiars, així com en les estratègies acordades per "reconstruir» noves quotidianitats.

Pel que respecta a les seves pràctiques espacials, veiem que aquestes són marcades profundament per una sensació constant de por, amenaça i vulne- 
rabilitat en l'espai públic, alimentada sovint pels discursos construïts pels mateixos mitjans de comunicació i les persones del seu entorn social. D’aquesta manera, s'observa que només les llars i els espais perfectament controlats i vigilats generen, en molts casos, un efecte tranquil.litzador. Les comparacions entre les ciutats espanyoles d'origen (percebudes com a llocs segurs i tranquils) i la ciutat llatinoamericana (percebuda com un lloc perillós) són inevitables, fins al punt que, per a moltes dones, la manca d'identificació amb la Ciutat de Mèxic esdevé una de les raons principals per desitjar tornar al país d'origen. A les àrees residencials on viuen, s'hi observa una doble dinàmica d'inclusió/exclusió de les famílies d'ingressos alts molt freqüent a les ciutats llatinoamericanes amb una forta segmentació social i urbana. D'acord amb Yeoh i Willis (2005b: 270), les elits transnacionals pertanyen molt més a l' "espai dels llocs» que no pas a l'"espai dels fluxos», atès que aquesta classe social (capitalista transnacional), malgrat la seva alta mobilitat, genera «noves pràctiques, relacions, xarxes i sensibilitats socials i culturals transnacionals» en un espai i un temps determinats.

\section{Referències bibliogràfiques}

AguiLAR, Adrián Guillermo (2002). «Las mega-ciudades y las periferias expandidas». EURE Revista Latinoamericana de Estudios Urbanos Regionales, 28, 85. [www.redalyc.com].

ARIZA, Marina (2000). Ya no soy la que dejé atrás: Mujeres migrantes en la República Dominicana. Ciutat de Mèxic: Instituto de Investigaciones Sociales y Plaza y Valdés.

ARIZPE, Lourdes i ARANDA, Josefina (1986). «Women workers in the strawberry agriculture in Mexico». A: LEACOCK, Eleanor i SAFA, Helen I. (comps.). Women s Work: Development and the Division of Labor and Gender. Massachussets: Bergin \& Garcey Publishers, 174-193.

AZNÁREZ, Juan Jesús (2007). «La "industria” del secuestro esquilma a América Latina». El Pais, diumenge, 17 de febrer de 2007.

BJÖRNBERG, Ulla i KolLIND, Anna-Karin (2003). «Discurso sobre igualdad de género en dos familias asalariadas. Exploración de aspectos multidimensionales». A: MeEntZen, Angela i GomÁrIZ, Enrique (comps.). Democracia de género, una propuesta inclusiva. El Salvador: Fundación Heinrich Böll, 151-180.

BONNEY, Norman i LOVE, John (1991). «Gender and migration: geographical mobility and the wife's sacrifice». The Sociological Review, 39 (2), 335-348.

BORJA, Jordi i MuXí, Zaida (2001). Espai públic: ciutat i ciutadania. Barcelona: Diputació de Barcelona.

BORSDORF, Axel (2003). «Cómo modelar el desarrollo y la dinámica de la ciudad latinoamericana». EURE Revista Latinoamericana de Estudios Urbanos Regionales, 29, 86, 37-49.

BOYD, Monica i PIKKOV, Deanna (2005). Gendered migration, Livelihood and entitlements: Migrant women in Canada and the United State. Ginebra: Research Institute for Social Development (Ocasional Paper; 6). [http://www.unrisd.org].

CAVOUNIDIS, Jennifer (2006). «Labor market impact of migration: Employment structures and the case of Greece». International Migration Review, 40 (3), 635-660. 
Chant, Sylvia i RADCliffe, Sarah A. (1992). «Migration \& development: The importance of gender». A: CHANT, Sylvia (coord.). Gender and migration in developing countries. Londres: Belhaven Press, 1-29.

CHELL, Victoria (2000). «Female migrants in Italy: Copying in a country of new migration». A: ANTHIAS, Floya i LAZARIDIS, Gabriella (comps.). Gender and migration in southern Europe: Women on the move. Oxford: Berg, 49-80.

CoOKe, Thomas J. (2003). «Family migration and the relative earnings of husbands and wives». Annals of the Association of American Geographers, 93 (2), 338-349.

CORnEliUs, Wayne (1992). «From soujournes to settlers: The changing profile of Mexican immigration to the United States». A: Bustamante, Jorge; ReYNOLDS, C. i HinOJOSA OJEDA, R. (comps.). US-Mexico Relations: Labor Market Interdependence. Stanford: Stanford University Press, 155-195.

Donato, Katherine M. (1992). «Undertanding US migration: Why some countries send women and others send men». A: GABACCIA, Donna (comp.). Seeking common ground: Multidisciplinary studies of immigrant women in the United States. Westport, CT: Greenwood Press, 159-184 (Contributions in Women s Studies; 129).

Donato, Katherine M.; Gabaccia, Donna; Holdaway, Jennifer; Manalansan, Martin i PESSAR, Patricia R. (2006). «A glass half full?: Gender in migration studies». International Migration Review, 40 (1), 3-26.

Durand, Jorge; Massey, Douglas S. i Zenteno, René M. (2001). «Mexican immigration to the United States: Continuties and changes». Latin American Research Review, 36 (1), 107-127.

FONER, Nancy (1997). «The immigrant family: Cultural legacies and cultural changes». International Migration Review, 31 (4), 961-974.

- (2001). «Benefits and burdens: Immigrant women and work in New York City». A: JAMES SimON, Rita (comp.). Immigrant women. New Brunswick: Transaction Publishers, 1-20.

García CANClini, Néstor (1995). Consumidores y ciudadanos: Conflictos multiculturales de la globalización. Mèxic: Grijalbo.

HalfacreE, Keith (1995). "Household migration and the structuration of patriarchy: evidence from the USA». Progress in Human Geography, 19 (2), 159-182.

- (2004). "A utopian imagination in migration's Terra Incognita? Acknowledging the non-economic worlds of migration decisión-making». Population, Space and Place, 10, 239-253.

Hiernaux, Daniel (1999). «Los frutos amargos de la globalización: expansión y reestructuración metropolitana de la ciudad de México». EURE Revista Latinoamericana de Estudios Urbanos Regionales, 25, 76. [www.redalyc.com].

Ho, Christina (2006). «Migration as feminisation? Chinese women's experiences of work and family in Australia». Journal of Ethnic and Migration Studies, 32 (3), 497-514.

Hondagneu-Sotelo, Pierrette (1994). Gendered transitions: Mexican experiences of immigration. Berkeley: University of California.

- (2001). Doméstica: Immigrant workers clearing and caring in the shadows of affluence. Berkeley: University of California Press.

INEGI (2008). Conteo de Población y Vivienda 2005. Ciutat de Mèxic: Instituto Nacional de Estadística, Geografía e Informática.

IREDALE, Robyn (2005). "Gender, immigration policies and accreditation: valuing the skills of professional women migrants». Geoforum, 36 (2), 155-166. 
JANOSHCKA, Michael (2002). «El nuevo modelo de la ciudad latinoamericana: fragmentación y privatización». EURE Revista Latinoamericana de Estudios Urbanos Regionales, 28, 85.

KOFMAN, Eleonore i PARVARTI, Raghuram (2005). «Editorial. Gender and skilled migrants: into and beyond the work place». Geoforum, 36 (2), 149-154.

LOZANO, Fernando (2002). «Migrantes de las ciudades: Nuevos modelos de la migración mexicana a Estados Unidos». A: García, Brígida (comp.). Población y sociedad al inicio del siglo XXI. Ciutat de Mèxic: El Colegio de México, 241-259.

MAN, Guida (2004). «Gender, work and migration: deskilling Chinese immigrant women in Canada». Women's Studies Internacional Forum, 27, 135-148.

MARCELli, Enrico A. i CORNELIUS, Wayne (2001). «The changing profile of Mexican migrants to the United States. New evidence from California and Mexico». Latin American Research Review, 36 (3), 105-131.

Mattos, Carlos A. de (2002). "Transformaciones de las ciudades latinoamericanas: ¿impactos de la globalización?». EURE Revista Latinoamericana de Estudios Urbanos Regionales, 28, 85. [www.redalyc.com]

MCDOWELL, Linda i COURT, Gill (1994). «Performing work, bodily representations in merchant banks». Environment and Planning D: Society and Space, 12 (6), 727-750.

MENDOZA, Cristóbal (2003). Labour immigration in southern Europe: African employment in Iberian labour markets. Aldershot: Ashgate.

- (2005). «La migración femenina en el contexto de cambio de patrón migratorio México-Estados Unidos: Aportes de cuatro encuestas mexicanas de los noventa». Encuentro internacional "La movilidad en femenino». Tànger, Marroc, 16-19 de novembre.

MendozA, Cristóbal i OrTiz Guitart, Anna (2006). «Hacer las Américas: Migrantes españoles de alta calificación en la Ciudad de México». Documents d’Anàlisi Geogràfica, 47, 93-114.

Momsen, Janet Henshall (1992). "Gender selectivity in Caribbean migration». A: CHANT, Sylvia (comp.). Gender and migration in developing countries. Londres: Belhaven Press, 73-90.

- (1999). «Maids on the move». A: Momsen, Janet Henshall (comp.). Gender, migration and domestic sector. Londres: Routledge, 1-21.

NAGEL, Caroline (2005). «Skilled migration in global cities from Others' perspectives: British Arabs identity politics and local embededdness». Geoforum, 36, 197-210.

OBerhauser, Ann (1997). "The home as "field": households and homework in rural Appalachia». A: JonES, Jean Paul III; NAST, Heidi J. i RoBERT, Susan M. (eds.). Thresholds in feminist geography: difference, methodology, representation. Lanham: Rowman \& Littlefield, 165-182.

OERTZEN, Eleonore von (2003). «Cada mujer en su lugar: Nueva división internacional del trabajo en la reproducción doméstica». A: MEENTZEN, Ángela i GOMÁRIZ, Enrique (comps.). Democracia de género, una propuesta inclusiva. El Salvador: Fundación Heinrich Böll, 181-197.

OrTIZ, Altagracia (1996). “"En la aguja y el pedal eché la hiel”: A history of Puerto Rican women in the garment industry in New York 1920-1980». A: ORTIZ, Altagracia (comp.). Puerto Rican women and work: Bridges in transnational labor. Filadèlfia: Temple University Press, 55-81.

Ortiz, Anna i MendozA, Cristóbal (2007). «Mujeres expatriadas en México: Trabajo, hogar y vida cotidiana». Migraciones Internacionales, 4 (2), 5-32. 
- (2008). «Vivir (en) la Ciudad de México: espacio vivido e imaginarios espaciales de un colectivo de migrantes de alta calificación». Latin America Research Review, 43 (1), 113-138.

PARnReiter, Christof (2002). «Ciudad de México: el camino hacia una ciudad global». EURE Revista Latinoamericana de Estudios Urbanos Regionales, 28 (85). [www.redalyc.com].

PEDRAZA, S. (1991). «Women and migration: The social consequences of gender». Annual Review of Sociology, 17, 303-327.

PERISTA, Heloísa (2000). «EU migrant women: migration, family life and professional trajectories». Papers, 60, 153-166.

Pessar, Patricia R. (1995). "On the homefront and in the workplace: Integrating immigrant women into feminist discourse». Anthropological Quartely, 68 (1), $37-42$.

Pessar, Patricia R. i Mahler, Sarah J. (2003). «Transnational migration: Bringing gender in». International Migration Review, 37 (3), 812-846.

PIPER, Nicola (2006). «Gendering the Politics of Migration». International Migration Review, 40 (1), 133-164

PRIETO, Yolanda (1992). «Cuban women in New Jersey: Gender relations and change». A: GABACCIA, Donna (comp.). Seeking common ground: Multidisciplinary studies of immigrant women in the United States. Westport: Greenwood Press, 185201 (Contributions in Women's Studies; 129).

PURKAYASTHA, Bandana (2005). «Skilled migration and cumulative disavantage: the case of highly qualified Asian Indian immigrant women in the US». Geoforum, 36, 181-196.

RAGHURAM, Parvati (2005). «The difference that skills make: Gender, family migration strategies and regulated labour markets». Journal of Ethnic and Migration Studies, 30 (2), 303-321.

Raghuram, Parvati i Kofman, Eleonore (2004). "Out of Asia: Skilling, re-skilling and deskilling of female migrants». Women's Studies International Forum, 27 (2), 95-100.

RiBAS MATEOS, Natalia (1999). Las presencias de la inmigración femenina: un recorrido por Filipinas, Gambia y Marruecos en Catalunya. Barcelona: Icaria.

SASSEN, Saskia (2000). Cities in a world economy. 2a ed. Thousand Oaks, California: Pine Forge Press.

SHARPE, Pamela (comp.) (2002). Women, gender and labour migration. Londres: Routledge.

SIN, Chih Hoong (2003). «Interviewing in "place": the socio-spatial construction of interview data». Area, 35 (3), 305-312.

SINKE, Suzanne M. (2006). «Gender and migration: historical perspectives». International Migration Review, 40 (1), 82-103.

SilveY, Rachel i LAWSON, Victoria (1999). "Placing the migrant». Annals of the Association of American Geographers, 89 (1), 121-132.

Strum, Philippa i Tarantolo, Danielle (eds.) (2003). Women immigrants in the United States. Washington DC: Woodrow Wilson International Center for Scholars.

ThANG, Leng Leng; MAClaCHLAN, Elizabeth i GODA, Miho (2002). «Expatriates on the margins: A study of Japanese women working in Singapore». Geoforum, 33, 539-551.

WilLIS, Katie i YeOH, Brenda S.A. (2002). «Gendering transnational communities: a comparison of Singaporean and British migrants in China». Geoforum, 33, 553-565. 
YEOH, Brenda S.A. i KHOO, Louisa-May (1998). "Home, work and community: skilled international migration and expatriate women in Singapore». International Migration, 36 (2), 159-186.

YEOH, Brenda S.A.; HuANG, Shirlena i Willis, Katie (2000). «Global cities, transnational flows and gender dimensions, the view from Singapore». Tijdschrift voor Economische en Sociale Geografie, 91 (2), 147-158.

YEOH, Brenda S.A. i WiLlis, Katie (2005a). «Singaporeans in China: transnational women elites and the negotiation of gendered identities». Geoforum, 36, 211-222.

- (2005b). "Singaporean and British transmigrants in China and the cultural political of "contact zones"”. Journal of Ethnic and Migration Studies, 31 (2), 269-285. 